\title{
The moderating effect of subjective norm in predicting intention to use urban green spaces: A study of Hong Kong
}

\begin{abstract}
People living in urban areas are encouraged to use urban green spaces (UGS) because of the physical, psychological and social benefits offered by the green environment to city dwellers. Prior studies have investigated the physical, socio-psychological and demographic factors in explaining the use of UGS; however, the moderating effect of social influence has rarely been examined. Based on the theory of planned behaviour, a model extending the predictors of behavioural intention was proposed in this study. Data were collected by a telephone survey conducted in Hong Kong. The results reveal that attitude, subjective norm, perceived behavioural control, and usefulness positively influence people's intention of using urban green areas. It was also proved that the interaction terms of usefulness and subjective norm, and perceived quality and subjective norm, negatively influence behavioural intention. Insightful implications for studying UGS behaviour, suggestions for urban planning and promotion of using urban green spaces are discussed.
\end{abstract}

Keywords: theory of planned behaviour; social influence; promotion; interaction; green spaces

\section{Introduction}

Encouraging the use of urban green spaces (UGS) has become a central issue on the political agenda due to the potential health and well-being benefits associated with nature exposure (De Vries, Verheij, Groenewegen, \& Spreeuwenberg, 2003; Nielsen \& Hansen, 2007; Schipperijn, Stigsdotter, Randrup, \& Troelsen, 2010; Van den Berg, Joyce, \& De Vries, 2012). The urban green areas offer environmental supports to people for physical activity and, in turn, have significant beneficial effects on physical health such as obesity prevention (De Vries, Van Dillen, Groenewegen, \& Spreeuwenberg, 2013; Hartig, Mitchell, de Vries, \& Frumkin, 2014; Koohsari et al., 2015; Lachowycz \& Jones, 2011; WHO, 2016). The green environment in the city positively influences people's psychological well-being (Hartig, Mang, \& Evans, 1991; Ulrich, 1981). It provides rejuvenating experience to people through a sense of peacefulness and relief (Kaplan, 1995), opportunities for restoration (Grahn \& Stigsdotter, 2010; Nordh, Hartig, Hagerhall, \& Fry, 2009), stress-reduction (Hartig et al., 2014; Van den Berg, Maas, Verheij, \& Groenewegen, 2010), and reducing negative emotions (Ulrich et al., 1991). In addition to health benefits, UGS can enhance social inclusiveness and help develop community attachment among users (Coley, Sullivan, \& Kuo, 1997; Maas, Van 
Dillen, Verheij, \& Groenewegen, 2009; Sugiyama, Leslie, Giles-Corti, \& Owen, 2008; Yung, Conejos, \& Chan, 2016).

Urban green spaces are defined here as vegetated open spaces that are publicly accessible, examples of UGS are parks, playgrounds, sitting-out areas, and gardens (Lo \& Jim, 2012; Schipperijn, Bentsen, Troelsen, Toftager, \& Stigsdotter, 2013; Wong, 2009). The wide range of benefits associated with UGS have attracted growing investigations from different fields, including urban studies, leisure research, and health research (Schipperijn, Stigsdotter, et al., 2010). Most of these studies have focused on identifying the appropriate design or physical features that would fulfill the needs of users and stimulate the use of UGS (e.g. Coen \& Ross, 2006; Kaczynski, Potwarka, Smale, \& Havitz, 2009; Schipperijn, Ekholm, et al., 2010). However, there has been a recent resurgence of interest in socio-personal aspects on UGS visiting behaviour. Lo and Jim (2010) suggested that UGS satisfy users through a range of experience; in addition to physical features of UGS, public authorities should develop an understanding of UGS utilization behaviour in relation to personal social life and psychological processes. Wan and Shen (2015b) further argued that by applying socio-psychological theories enables researchers to conceptualize and garner a deeper understanding of the complexity of users' evaluative processes of using UGS.

Prior studies have stressed the importance of social context, influence, needs, and qualities in determining the participation of leisure activity. Raymore (2002) proposed that individuals and groups appeared in the social context, labeled as interpersonal facilitators, could shape our choices and enhance participation in leisure (p. 43). Lo and Jim (2010) provided evidence to the argument by demonstrating a positive correlation between neighborhood relationship and social cohesiveness and individuals' frequency of park visit. Having various activities with friends and family is one of the major reasons for visiting UGS (Schipperijn, Ekholm, et al., 2010). Open spaces in urban setting also possess different social meanings; for example, elderly would consider public open spaces as a place for maintaining their social connections (Yung et al., 2016). Discussions and findings in the literature suggested that social influence may serve as a facilitator of visiting UGS. Further, attitude-behaviour study in other fields have proposed and tested the moderating effect of social factor, e.g. peer influence and social support; however, the effect has not been tested in the field of UGS visiting behaviour. Thus, a knowledge gap of social factor in relation to UGS usage found in the current literature directs our attention to further examination of the issue.

Starting from the above considerations, this study aims at understanding socio-psychological factors that influence the decision of visiting urban green areas, and the social processes which regulate usage patterns in connection with citizens' level of appreciation of urban 
green spaces. First, an extended research model which is based on the theory of planned behavior (TPB) proposed by Ajzen (1991) and incorporates two additional antecedents, namely usefulness and perceived quality, is developed for investigating the intention of using urban green spaces. Second, the study will examine the moderating effect of subjective norm on relationship between constructs of the extended research model and behavioural intention of using UGS. By comprehending the intricacies of factors that drive the green spaces usage decision-making processes, the present study is expected to offer advantages to both policy authorities and citizens. The results and implications facilitate the identification of physical, psychological, and social needs of users, and promote informed decisions in urban planning. The urban environment which has fulfilled the needs of citizens can enhance UGS visitation and, in turn, promotes health and living quality of city dwellers.

\section{Research Framework and Hypotheses Development}

\subsection{Theory of planned behaviour (TPB)}

Ajzen (1991) proposed that the TPB is a general theory that can be applied to explain all kinds of behaviour. The theory postulates that behavioural intention is a function of attitude, subjective norm, and perceived behavioural control, and it is an immediate predictor of actual behaviour. The TPB is described as a parsimonious theoretical framework that includes key predictors with precise operational definition of each construct (Armitage \& Conner, 2001; Heath \& Gifford, 2002). The efficacy of the TPB in explaining behaviour has been empirically tested in a wide range of behavioural domains (Armitage \& Conner, 2001); for instance, recycling practice (Wan, Shen, \& Yu, 2014), transportation mode (Heath \& Gifford, 2002), use of online systems (Shih \& Fang, 2004), and food choice (Berg, Jonsson, \& Conner, 2000). The popularity of making use of the TPB in attitude-behaviour study has established the ground for research on health behaviour including the use of UGS (e.g. Glanz, Rimer, \& Viswanath, 2008; Rhodes, Brown, \& McIntyre, 2006; Wang, Brown, Liu, \& Mateo-Babiano, 2015).

Attitude (ATT) is the extent of an individual's positive or negative disposition towards a target behaviour (Fishbein \& Ajzen, 1975). Enhanced level of behavioural intention is originated from a favorable attitude towards the behaviour of interest. Carrus, Passafaro, and Bonnes (2004) developed an attitudinal measurement for urban green spaces which broadly measures individuals' appreciation of human-nature integration in urban areas. The captured values are general attitude towards the importance of natural elements in urban settings, such as stress relief and improvement of social relationships. The measurement was validated and proved adequately covering the complexity of attitude and considered as a useful tool for 
supporting urban planning decisions (Bonnes, Passafaro, \& Carrus, 2011). Therefore, the attitudinal measurement towards urban green spaces is considered as appropriate to be applied in this study.

Subjective Norm (SN) is an individual's perceived influence by other individuals or groups that are important or close to him / her (like friends, peers, neighbors) (Fishbein \& Ajzen, 1975). The social cognitive theory developed by Bandura (1989) suggested that an individual's behavior is influenced by his / her observation about others' behaviour in a particular setting. Cialdini, Kallgren, and Reno (1991) further investigated the influence of social norms and differentiated two types of social influence, namely injunctive norms and descriptive norms. Injunctive norms refer to the behaviour commonly approved or disapproved in a society or community which is equivalent to the subjective norm in TPB (Heath \& Gifford, 2002), while descriptive norms refer to the behaviour shown by most of the members in a specific social setting. Although some studies suggested that descriptive norms exert a stronger influence on people's behaviour than injunctive norms do (Cialdini, Reno, \& Kallgren, 1990; Keizer, Lindenberg, \& Steg, 2011), Schultz, Nolan, Cialdini, Goldstein, and Griskevicius (2007) pointed out that persuasive appeal of norms depends on specific contexts and individuals, and descriptive norms function only when the behaviour is being observed in an immediate context (Manning, 2009; Smith et al., 2012). The present study therefore focuses on subjective norm as originally defined and operationalized by Ajzen (1991) which is similar to the injunctive norms defined by Cialdini et al. (1991).

Perceived Behavioural Control (PBC) refers to an individual's perceived ability to perform behaviour (Ajzen, 1991). Do Valle, Rebelo, Reis, and Menezes (2005) identified two key dimensions of PBC in their study about recycling behaviour that external conditions refer to the convenience and facilitation of performing behaviour (e.g. location, facilities); and internal conditions are individual's perceived knowledge and ability.

The TPB suggests that behavioural intention can subsequently predict actual behaviour of individuals (Ajzen, 1991; Ajzen \& Madden, 1986), and there is a highly accurate established link between behavioural intention and behaviour (Ajzen, 1988, p. 113). In the current study, behavioural intention is operationalized as self-reported future plans and intentions to visit UGS, and this has been commonly used to measure intention of performing a certain behaviour in different research fields (Bamberg, Ajzen, \& Schmidt, 2003; Chan, 1998; Cheung \& Vogel, 2013; Shih \& Fang, 2004; Wan, Cheung, \& Shen, 2012).

Hypothesis 1 (H1): Attitude will influence intention to use UGS.

Hypothesis 2 (H2): Subjective norm will influence intention to use UGS. 
Hypothesis 3 (H3): Perceived behavioural control will influence intention to use UGS.

Ajzen (1991) mentioned that the TPB is flexible to include additional variables that contribute to explain behavioural intention or behaviour. A significant body of research on attitude-behaviour has added predictors to the TPB to improve the explanatory power of their extended models, for example, moral and awareness of consequences were included in the TPB to explain recycling behaviour (Chen \& Tung, 2010; Wan et al., 2014), self-identity and social support were added in study about physical activity (Hamilton \& White, 2008), and self-efficacy in healthy eating (Povey, Conner, Sparks, James, \& Shepherd, 2000). In the present study, two additional variables would be added to the TPB, namely usefulness and perceived quality for examining the use of urban green spaces.

\subsection{Usefulness (USE)}

Usefulness is defined as individuals' perceived benefits of using UGS, such as relaxation; it is a measurement scale for UGS attitude and it is found to be inter-correlated with individuals' behaviour of using urban green areas (Balram \& Dragićević, 2005). A detailed elucidation of the concept is scattered among current literature. Stern (1992) argued that whether individuals perform environmental behaviour is a function of their perceived costs and benefits of performing a certain behaviour. In the study of recycling behaviour, Davies, Foxall, and Pallister (2002) illustrated that the likelihood to do recycling would be increased if individuals were aware of the environmental and societal benefits of recycling. Similarly, the TPB assumes that an individual is a "utility-maximizing actor" and he / she would select an alternative with the most positive behavioural consequence (Bamberg \& Schmidt, 2003, p. 267).

Usefulness is specific attitude towards UGS usage and emphasizes on benefits, costs, or consequences associated with the behaviour, for instance, recreation and improved living quality. It is distinguished from the aforementioned attitudinal measurement developed by Carrus et al. (2004) which elicits general attitude towards urban greenery (i.e. an object) based on common appreciation of green environments in urban settings. Furthermore, there are two distinct types of attitude according to Ajzen and Driver (1992), namely instrumental attitude and experiential attitude. Usefulness can be considered as instrumental attitude which denotes individuals' consciousness of outcomes of performing the target behaviour (e.g. net benefits or awareness of consequences), while experiential attitude is defined as individuals' affective feelings of performing behaviour (e.g. good, pleasant). 
Taking the interpretation into account, usefulness is specific and instrumental attitude that if an individual perceives more positive consequences of using UGS, he / she is more likely to visit urban green areas. The following hypothesis is proposed.

Hypothesis 4 (H4): Usefulness will influence intention to use UGS.

\subsection{Perceived Quality (PQ)}

The perceived quality of UGS in neighbourhood positively contributes to residents' sense of community (Francis, Giles-Corti, Wood, \& Knuiman, 2012). In addition to emotional attachment, Sugiyama and Thompson (2007) defined environmental supportiveness as how the environment facilitates or hinders behaviour, that include environmental cues and aesthetic features which attract activity and behaviour (Thompson, 2013). UGS may contain attractive environmental features driving or motivating behaviour, such as well-designed and good quality of facilities. Therefore, if the quality of UGS is positively perceived, individuals' intention to use or perform a certain activity in urban green spaces will be increased. Bonnes et al. (2011) proposed a construct of perceived quality of UGS that was proved to be significantly correlated with frequency of usage. The construct captures individuals' affective responses towards UGS and focuses on perceived adequacy, conditions, equipment, and accessibility of UGS. Thus, the following hypothesis is proposed.

Hypothesis 5 (H5): Perceived quality will influence intention to use UGS.

\subsection{The moderating effect of subjective norm}

People learn and act with reference to their observation about others' behaviour (Bandura, 1989); this highlights the importance of subjective norm in the TPB, which implies that influence from significant others act on individuals' behaviour (Ajzen, 1991; Fishbein \& Ajzen, 1975). In UGS study, Schipperijn, Stigsdotter, et al. (2010) argued that public authorities should be well aware of sociocultural facilitators besides physical environment in determining UGS visit. More precisely, individuals or groups may serve as interpersonal facilitators that increase participation in leisure activities (Raymore, 2002). Empirically, Lo and Jim (2010) demonstrated that community quality is a more significant predictor of individuals UGS visiting behaviour compared with physical aspects of parks. Other than direct effect, subjective norm may operate in a more complicated mechanism than the original TPB has suggested in determining behavioural intention. For instance, Caldwell and Darling (1999) found in their study that the relationship between partying among adolescents and substance use are moderated by peers and resistance to peer pressure. Recently, Wan, 
Shen, and Choi (2017) examined the interaction effect of attitude and subjective norm in recycling intention, and demonstrated that people with positive experiential attitudes are more likely to engage in recycling practices under the influence of subjective norm. The above literature put forward that subjective norm may interact with other variables and result in interaction effect that further shapes individuals' behaviour. Therefore, we propose to investigate moderating effect of subjective norm in this study.

Consider that an individual carries a favourable attitude towards urban greenery, but feels that the subjective norm does not encourage or promote the use of UGS; the individual is likely to have low intention to visit urban green spaces. On the contrary, if the individual has weak attitude towards urban greenery, while under effective facilitation by the subjective norm, he / she would still have low intention to make a visit. In the field of health psychology, perceived social support was proved as a positive moderator of the relationship between attitude and intention of healthy eating (Povey et al., 2000). Similarly, the study about e-learning technologies by Cheung and Vogel (2013) demonstrated that subjective norm moderates such relationship. Therefore, the following hypothesis is proposed.

Hypothesis 6 (H6): Subjective norm will have moderating effect on the relationship between attitude and behavioural intention.

In relation to PBC, Ajzen (1991) suggested that PBC increases an individual's motivation to perform a certain behaviour, this is considered as perceived competence of performing behaviour. Povey et al. (2000) found that perceived social support, in the context of healthy eating, negatively moderates the relationship between $\mathrm{PBC}$ and intention. If an individual perceives a higher level of assistance and information through social contacts with individuals or groups, his / her perceived PBC will become a weaker predictor of behavioural intention. Similarly in the field of UGS utilization behaviour, if an individual experiences a strong subjective norm (an external influence), the intrinsic knowledge and ability would become less important. The following hypothesis is proposed.

Hypothesis 7 (H7): Subjective norm will have moderating effect on the relationship between $\mathrm{PBC}$ and behavioural intention.

Subjective norm had also been found to be a moderator in other fields. In a study on computing users conducted by Chi, Yeh, and Hung (2012), subjective norm is a positive moderator of the relationship between perceived risk of a computer system and usage intention of that system. It implies that if an individual is highly influenced by subjective norm, his / her usage intention will not be influenced, even with an increase of perceived risk. 
A similar result was suggested by Lam, Baum, and Pine (2003) in tourism research; the study identified that subjective norm increases the strength (i.e. positively moderate) of the relationship between unmet job expectations and job satisfaction. It is interpreted as an individual who strongly complies with subjective norm is more likely to tolerate unsatisfactory work and atmosphere. Although these studies are not directly related to leisure research or the use of urban green spaces, they suggested that subjective norm has a powerful influence on behaviour that makes individuals ameliorate negative circumstances. Therefore, we proposed that if an individual is highly influenced by subjective norms, the impact of usefulness and perceived quality of UGS would be weakened in predicting intention of visiting UGS, making the influences of usefulness and perceived quality become less important. The following hypotheses are proposed.

Hypothesis 8 (H8): Subjective norm will have moderating effect on the relationship between usefulness and behavioural intention.

Hypothesis 9 (H9): Subjective norm will have moderating effect on the relationship between perceived quality and behavioural intention.

Drawing upon the aforementioned literature, a research model is formulated in Figure 1.

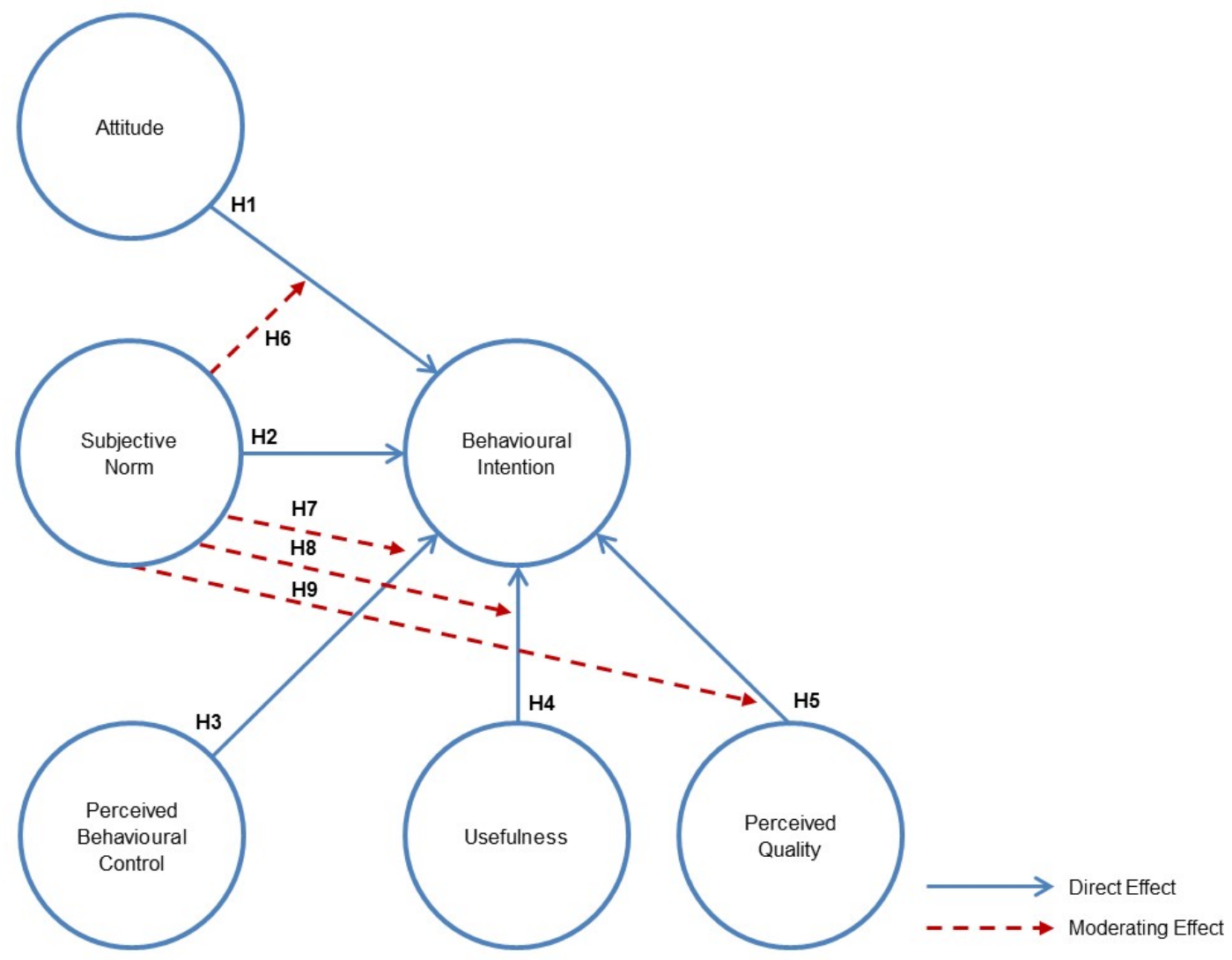

Figure 1 The research model 


\section{Questionnaire Development and Data Collection}

The questionnaire was designed by drawing reference to literature of the TPB theoretical framework (Ajzen, 1991) and urban green spaces as discussed above (Balram and Dragićević, 2005; Bonnes et al., 2011; Carrus et al., 2004). In this study, a seven-point Likert scale was used to measure the components of the research model $(7=$ strongly agree; $1=$ strongly disagree). The questionnaire included measurement items of (i) five independent variables: attitude, subjective norm, perceived behavioural control, usefulness, and perceived quality; (ii) one dependent variable (i.e. behavioural intention); (iii) the demographic background of the respondents (i.e. age, gender, education level and personal monthly income). The details of the questionnaire items are presented in Appendix A.

Although the survey methods such as telephone survey, mail survey, street interview, and web survey allow researchers to have randomized process in sampling (Malhotra, 2012; Neuman, 2013), we have chosen telephone survey for data collection in this study. Telephone interview can result in a higher response rate compared to mail and web survey; it is also less expensive method to collect data than street interview. In addition, the coverage of landline telephone in Hong Kong is $100.3 \%$ (i.e. 100.3 lines per 100 households); thus, data collection using telephone survey is a valid, though not perfect, method to reach the local population (Lau, 2015). Using computer-assisted telephone interviews, the system randomly selected telephone numbers from a residential telephone directory produced by a telecommunication company in Hong Kong. For every successful telephone call was made, the interviewer would check whether there were any persons aged over 18 in the household. In case of more than one potential respondents, "next birthday" rule would be used to identify a respondent.

263 valid responses were collected and the response rate was $84.8 \%$ based on the formula by Massey, O'Connor, and Krotki (1997), i.e. successful completion / (total no. of calls - out of scope). Out of scope includes fax machine numbers, un-contactable numbers, business numbers, communication problems, and ineligible household (i.e. no adults). The number of 263 responses fulfilled the sample size requirement suggested by Hair, Ringle, and Sarstedt (2011), i.e. 10 times of the largest number of hypothesised relationships $\left(n_{p}\right)$ (i.e. 9$)$ directed to the dependent variable behavioural intention (i.e. 90). This also fulfilled the required sample size of 166 based on statistical power analysis using the $\mathrm{G}^{*}$ Power 3.1 software (Akter, D'Ambra, \& Ray, 2011; Faul, Erdfelder, Lang, \& Buchner, 2007) $\left(\alpha=0.05 ; \mathrm{f}^{2}=0.15 ; \mathrm{n}_{\mathrm{p}}=9\right)$. Therefore, the sample size of 263 can be considered as statistically robust. 
The respondent and the population profiles (Census and Statistics Department, 2011) are presented in Table 1. Chi-square tests were used to assess whether the sample composition was significantly different from the composition of the city's population. The results revealed that the sample and population did not have significant differences in terms of gender, age, and monthly income $(p>0.05)$. However, the education level of the sample deviated from the census data $(p<0.05)$ that the group with low education level, i.e., primary or below, was underrepresented.

Table 1 Respondent Profile and the Corresponding Population Profile

\begin{tabular}{|c|c|c|c|c|}
\hline Demographic Variable & Sample (N) & Sample (\%) & Population (\%) & Difference \\
\hline \multicolumn{5}{|c|}{$\operatorname{Gender}(\chi 2=0.73 ; p>0.05)$} \\
\hline Male & 108 & $41.06 \%$ & $46.71 \%$ & $-5.64 \%$ \\
\hline Female & 155 & $58.94 \%$ & $53.29 \%$ & $5.64 \%$ \\
\hline \multicolumn{5}{|l|}{$\operatorname{Age}\left(\chi^{2}=0.27 ; p>0.05\right)$} \\
\hline $18-24$ & 36 & $13.69 \%$ & $10.45 \%$ & $3.24 \%$ \\
\hline $25-34$ & 42 & $15.97 \%$ & $18.07 \%$ & $-2.10 \%$ \\
\hline $35-44$ & 48 & $18.25 \%$ & $18.92 \%$ & $-0.67 \%$ \\
\hline $45-54$ & 62 & $23.57 \%$ & $21.49 \%$ & $2.08 \%$ \\
\hline $55-64$ & 48 & $18.25 \%$ & $15.38 \%$ & $2.87 \%$ \\
\hline$>=65$ & 27 & $10.27 \%$ & $15.69 \%$ & $-5.42 \%$ \\
\hline \multicolumn{5}{|c|}{ Education Level $\left(\chi^{2}=21.51 ; p<0.05\right)$} \\
\hline Primary & 30 & $11.41 \%$ & $37.60 \%$ & $-26.19 \%$ \\
\hline Secondary & 128 & $48.67 \%$ & $41.38 \%$ & $7.29 \%$ \\
\hline Post-secondary & 105 & $39.92 \%$ & $21.02 \%$ & $18.90 \%$ \\
\hline \multicolumn{5}{|c|}{ Personal Monthly Income $(\mathrm{HK} \$)\left(\chi^{2}=0.16 ; p>0.05\right)$} \\
\hline$<10 \mathrm{~K}$ & 119 & $45.25 \%$ & $39.98 \%$ & $5.27 \%$ \\
\hline $10-20 \mathrm{~K}$ & 65 & $24.71 \%$ & $32.87 \%$ & $-8.15 \%$ \\
\hline $20-30 \mathrm{~K}$ & 30 & $11.41 \%$ & $12.01 \%$ & $-0.60 \%$ \\
\hline $30-40 \mathrm{~K}$ & 16 & $6.08 \%$ & $6.10 \%$ & $-0.01 \%$ \\
\hline$>40 \mathrm{~K}$ & 28 & $10.65 \%$ & $9.05 \%$ & $1.60 \%$ \\
\hline refused to answer & 5 & $1.90 \%$ & - & - \\
\hline
\end{tabular}




\section{Data Analysis and Findings}

Structural equation modeling (SEM) measures statistical relationships among constructs with multiple measurement items (Chin, 1998; Jöreskog \& Sörbom, 1989). Two major SEM approaches were commonly used in statistical analysis, i.e. covariance-based approach and variance-based partial least squares (PLS) approach (Hair et al., 2011). PLS is employed for this study because it is more suitable for analysis involving a large number of relationships (e.g. 10) and small sample sizes (Hair et al., 2011; Lu, Kwan, Thomas, \& Cedzynski, 2011; Reinartz, Haenlein, \& Henseler, 2009). The "SmartPLS 2.0" software (Ringle, Wende, \& Will, 2005) was used.

\subsection{Measurement model}

The first step of PLS analysis is to compute the measurement model that evaluate whether the measurement items are statistically reliable and valid for measuring the constructs specified in the model. In this step, the convergent and discriminant validity of the constructs should be assessed. Convergent validity of constructs means that the measurement items in the same constructs should be highly correlated. Four statistical criteria need to be fulfilled for convergent validity (Chin, 1998; Fornell \& Larcker, 1981; Hair, Black, Babin, \& Anderson, 2013). These criteria include: (i) all loading of indicators within a construct should be higher than 0.5 ; (ii) composite reliability of the constructs should be higher than 0.7; (iii) average variance extracted (AVE) of the constructs should be higher than 0.5: (iv) Cronbach's alpha of the constructs should be higher than 0.7 . All constructs in this study met the statistical requirements for convergent validity (Table 2). Furthermore, discriminant validity refers to that measurement items within different constructs that should be unrelated. To assess this, Chin (1998) suggested that the square root of a construct's AVE should be larger than the coefficient of correlations between the specific construct and other constructs in the model. All constructs in this study showed adequate discriminant validity (Table 3). 
Table 2 The Measurement Model

\begin{tabular}{|c|c|c|c|c|c|}
\hline Constructs & Indicators & $\begin{array}{c}\text { Factor } \\
\text { Loadings }\end{array}$ & $\begin{array}{c}\text { Average } \\
\text { Variance } \\
\text { Extracted } \\
\text { (AVE) }\end{array}$ & $\begin{array}{c}\text { Composite } \\
\text { Reliability } \\
\text { (CR) }\end{array}$ & $\begin{array}{c}\text { Cronbach's } \\
\text { Alpha } \\
(\boldsymbol{\alpha})\end{array}$ \\
\hline Attitude (ATT) & $\begin{array}{l}\text { ATT1 } \\
\text { ATT2 } \\
\text { ATT3 } \\
\text { ATT4 } \\
\text { ATT5 }\end{array}$ & $\begin{array}{l}0.852 \\
0.876 \\
0.906 \\
0.889 \\
0.799 \\
\end{array}$ & 0.749 & 0.937 & 0.916 \\
\hline Subjective Norm (SN) & $\begin{array}{l}\text { SN1 } \\
\text { SN2 } \\
\text { SN3 } \\
\text { SN4 } \\
\end{array}$ & $\begin{array}{l}0.697 \\
0.932 \\
0.939 \\
0.920 \\
\end{array}$ & 0.771 & 0.930 & 0.896 \\
\hline $\begin{array}{l}\text { Perceived Behavioural Control } \\
\text { (PBC) }\end{array}$ & $\begin{array}{l}\text { PBC1 } \\
\text { PBC2 } \\
\text { PBC3 } \\
\text { PBC4 } \\
\text { PBC5 } \\
\text { PBC6 }\end{array}$ & $\begin{array}{l}0.791 \\
0.762 \\
0.821 \\
0.740 \\
0.694 \\
0.687\end{array}$ & 0.564 & 0.885 & 0.849 \\
\hline Usefulness (USE) & $\begin{array}{l}\text { USE1 } \\
\text { USE2 } \\
\text { USE3 } \\
\text { USE4 }\end{array}$ & $\begin{array}{l}0.890 \\
0.898 \\
0.874 \\
0.738 \\
\end{array}$ & 0.726 & 0.913 & 0.873 \\
\hline Perceived Quality (PQ) & $\begin{array}{l}\text { PQ1 } \\
\text { PQ2 } \\
\text { PQ3 } \\
\text { PQ4 }\end{array}$ & $\begin{array}{l}0.827 \\
0.868 \\
0.891 \\
0.641 \\
\end{array}$ & 0.661 & 0.885 & 0.825 \\
\hline Behavioural Intention (BI) & $\begin{array}{l}\mathrm{BI} 1 \\
\mathrm{BI} 2 \\
\mathrm{BI} 3\end{array}$ & $\begin{array}{l}0.862 \\
0.902 \\
0.899 \\
\end{array}$ & 0.788 & 0.918 & 0.865 \\
\hline
\end{tabular}

Table 3 Correlations among Constructs

\begin{tabular}{lllllll}
\hline Constructs & ATT & SN & PBC & USE & PQ & BI \\
\hline ATT & $\mathbf{0 . 8 6 5}$ & & & & & \\
SN & 0.574 & $\mathbf{0 . 8 7 8}$ & & & & \\
PBC & 0.467 & 0.508 & $\mathbf{0 . 7 5 1}$ & & & \\
USE & 0.609 & 0.530 & 0.545 & $\mathbf{0 . 8 5 2}$ & $\mathbf{0 . 8 1 3}$ & $\mathbf{0 . 8 8 8}$ \\
PQ & 0.390 & 0.416 & 0.591 & 0.589 & 0.379 & 0.551 \\
BI & 0.505 & 0.546 & 0.537 & & & \\
\hline
\end{tabular}

Note: Figures in bold are the square roots of the average variance extracted (AVE). 


\subsection{Structural model}

Subsequent to the assessment of measurement model, the PLS structural model should be assessed. This step involves assessment of the statistical significance of the hypothesized relationships specified in the research model. Path significance can be determined by a bootstrap resampling process with cases (the responses collected by the telephone survey) and 1000 subsamples (Chin, 1998). Table 4 lists the results of the analysis. 
Table 4 Testing results of the main effects and moderating effects of subjective norm

\begin{tabular}{|c|c|c|c|c|c|c|c|c|c|c|c|c|c|}
\hline \multirow[b]{2}{*}{ Paths } & & \multicolumn{3}{|c|}{ Model 1} & \multicolumn{3}{|c|}{ Model 2} & \multicolumn{3}{|c|}{ Model 3} & \multicolumn{3}{|c|}{ Model 4} \\
\hline & & $\beta$ & $t$-value & Sig. & $\beta$ & $t$-value & Sig. & $\beta$ & $t$-value & Sig. & $\beta$ & $t$-value & Sig. \\
\hline H1: & $\mathrm{ATT} \rightarrow \mathrm{BI}$ & 0.208 & 3.462 & $* * *$ & 0.119 & 1.819 & $*$ & -0.021 & 0.164 & & 0.018 & 0.139 & \\
\hline $\mathrm{H} 2$ : & $\mathrm{SN} \rightarrow \mathrm{BI}$ & 0.273 & 3.877 & $* * *$ & 0.240 & 3.570 & $* * *$ & 0.611 & 2.679 & $* *$ & 0.602 & 2.746 & $* *$ \\
\hline H3: & $\mathrm{PBC} \rightarrow \mathrm{BI}$ & 0.299 & 4.872 & $* * *$ & 0.266 & 3.835 & $* * *$ & 0.094 & 0.621 & & 0.031 & 0.233 & \\
\hline H4: & $\mathrm{USE} \rightarrow \mathrm{BI}$ & & & & 0.248 & 3.401 & $* * *$ & 0.589 & 2.670 & $* *$ & 0.576 & 2.623 & $* *$ \\
\hline H5: & $\mathrm{PQ} \rightarrow \mathrm{BI}$ & & & & -0.071 & 1.270 & & 0.336 & 1.884 & $*$ & 0.317 & 1.682 & $*$ \\
\hline H6: & $\mathrm{ATT} \times \mathrm{SN} \rightarrow \mathrm{BI}$ & & & & & & & 0.251 & 0.861 & & 0.158 & 0.592 & \\
\hline H7: & $\mathrm{PBC} \times \mathrm{SN} \rightarrow \mathrm{BI}$ & & & & & & & 0.408 & 1.335 & & 0.517 & 1.582 & \\
\hline H8: & $\mathrm{USE} \times \mathrm{SN} \rightarrow \mathrm{BI}$ & & & & & & & -0.633 & 1.844 & $*$ & -0.591 & 1.793 & $*$ \\
\hline H9: & $\mathrm{PQ} \times \mathrm{SN} \rightarrow \mathrm{BI}$ & & & & & & & -0.718 & 2.247 & $*$ & -0.683 & 1.989 & $*$ \\
\hline & Gender $\rightarrow$ BI & & & & & & & & & & -0.102 & 2.356 & $* *$ \\
\hline & Age $\rightarrow$ BI & & & & & & & & & & -0.102 & 2.147 & $*$ \\
\hline & Educational Level $\rightarrow$ BI & & & & & & & & & & 0.021 & 0.566 & \\
\hline & Income $\rightarrow$ BI & & & & & & & & & & -0.008 & 0.262 & \\
\hline & $R^{2}$ & & 0.413 & & & 0.444 & & & 0.475 & & & 0.500 & \\
\hline & $f^{2}$ & & & & & 0.053 & & & 0.056 & & & 0.048 & \\
\hline
\end{tabular}

$* p<0.05, * * p<0.01, * * * p<0.001$ 
Hair et al. (2011) suggested that $R^{2}$ values of $0.25,0.50$ and 0.75 in PLS analysis can be interpreted as weak, moderate and substantial respectively. All the four models showed moderate amount of variance, $R^{2}$ values ranged from 0.413 to 0.500 , in behavioural intention is explained by the factors specified.

Model 1, including the three variables in the TPB, accounted for $41.3 \%$ of the variance in the main effects of intention to use urban green spaces. This showed behavioural intention can be explained by attitude $(\beta=0.208, p<0.001)$, subjective norm $(\beta=0.273, p<0.001)$ and perceived behavioural control $(\beta=0.299, p<0.001)$.

Model 2 included two additional variables, namely usefulness and perceived quality. By adding the two variables, Model 2 accounted for $44.4 \%$ of the variance in intention to visit urban green spaces. It revealed that, in addition to the three TPB variables, usefulness $(\beta=$ $0.248, p<0.001$ ) was positively correlated with behavioural intention; on the contrary, perceived quality was not statistically significant at $p=0.05$. Cohen (1988) proposed that the effect of a latent predictor can be calculated using the formula $f^{2}=\left(R^{2}\right.$ incl $\left.-R^{2}{ }_{\text {excl }}\right) /\left(1-R^{2}\right.$ incl $)$, and the values of $0.02,0.15$, and 0.35 could be interpreted as small, medium, and large effect respectively. The value of effect $\left(f^{2}\right)$ for the two additional links in Model 2 was 0.053 which represented a small effect; however, Limayem and Cheung (2011) suggested that the low value does not necessarily imply an unimportant effect. To further understand the impacts of the two additional predictors, percentage contribution to $R^{2}$ value was computed based on correlations between the predictors and the dependent variable (Tenenhaus, Vinzi, Chatelin, $\&$ Lauro, 2005). Table 5 shows the $R^{2}$ value contribution of the five independent variables. For this model, PBC, followed by USE and $\mathrm{SN}$, were the strongest variables in the prediction of intention, each contributing around $30 \%$ to the $R^{2}$ value. In addition, ATT contributed $13.58 \%$ to the $R^{2}$ value.

Table 5 Explanation of variance $\left(R^{2}\right)$ of behavioural intentions

\begin{tabular}{lccc}
\hline Block & $\boldsymbol{\beta}$ & $\boldsymbol{r}$ & Contribution to $\boldsymbol{R}^{\mathbf{2}}$ \\
\hline ATT & 0.119 & 0.505 & $13.58 \%$ \\
SN & 0.240 & 0.546 & $29.54 \%$ \\
PBC & 0.266 & 0.537 & $32.11 \%$ \\
USE & 0.248 & 0.551 & $30.85 \%$ \\
PQ & -0.071 & 0.379 & $-6.07 \%$ \\
\hline
\end{tabular}

Model 3 accounted for $47.5 \%$ of variance in behavioural intention after the moderating effect of subjective norm was included. The intention to use urban green spaces was predicted by subjective norm $(\beta=0.602, p<0.01)$, usefulness $(\beta=0.576, p<0.01)$ and perceived quality $(\beta=0.317, p<0.05)$, supporting the hypothesis H2, H4 and H5. However, the results showed 
that attitude and perceived behavioural control were not statistically significant on the intention to use UGS, thus $\mathrm{H} 1$ and $\mathrm{H} 3$ were rejected.

The value of the effect $\left(f^{2}\right)$ for the moderating links was 0.056 which represented a small effect; but two significant moderating paths, $\mathrm{USE} \times \mathrm{SN}$ and $\mathrm{PQ} \times \mathrm{SN}$, indicated strong beta values of -0.633 and -0.718 respectively. The subjective norm had negative moderating effect on the link between usefulness and behavioural intention $(\beta=-0.633, p<0.05)$. This implied that the effect of usefulness on behavioural intention would be weaken when an individual perceives a high level of social influence. Though the interaction term $\mathrm{PQ} \times \mathrm{SN}$ significantly influenced behavioural intention $(\beta=-0.718, p<0.05)$, the insignificant link between perceived quality and intention revealed in Model 2 suggested that there is no direct effect of perceived quality on behavioural intention; instead, Model 3 results revealed that the effect of perceived quality on behavioural intention is moderated by the level of subjective norm. Simple slope analyses were performed for the two significant interaction terms (Figure 2 and 3 ). The figures illustrated that under strong influence of subjective norm, people are more likely to use UGS even they perceive low level of usefulness or quality about UGS.

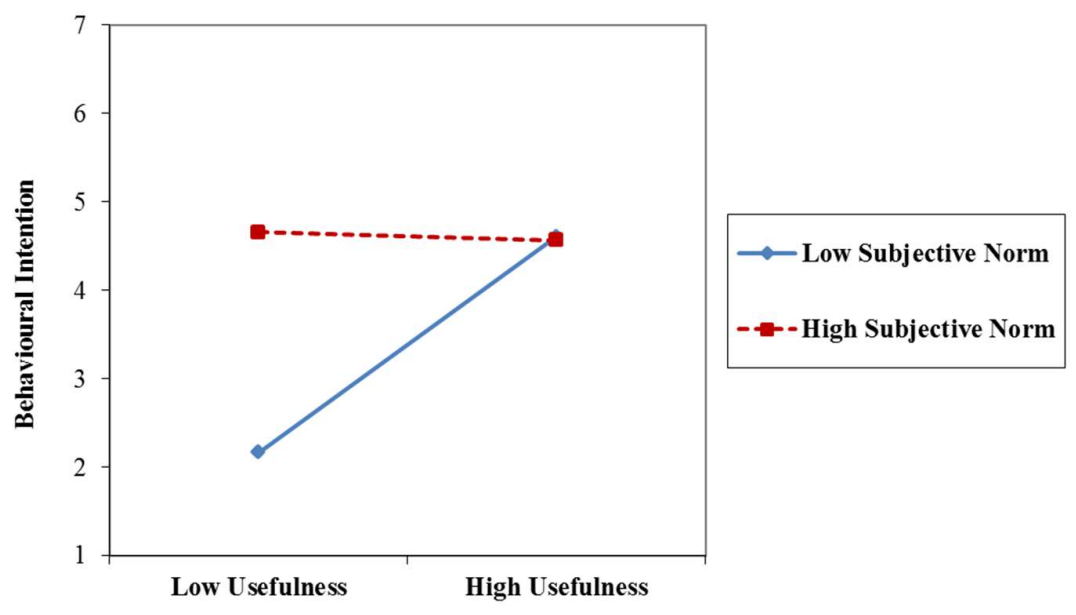

Figure 2 The interaction of usefulness and subjective norm on behavioural intention 


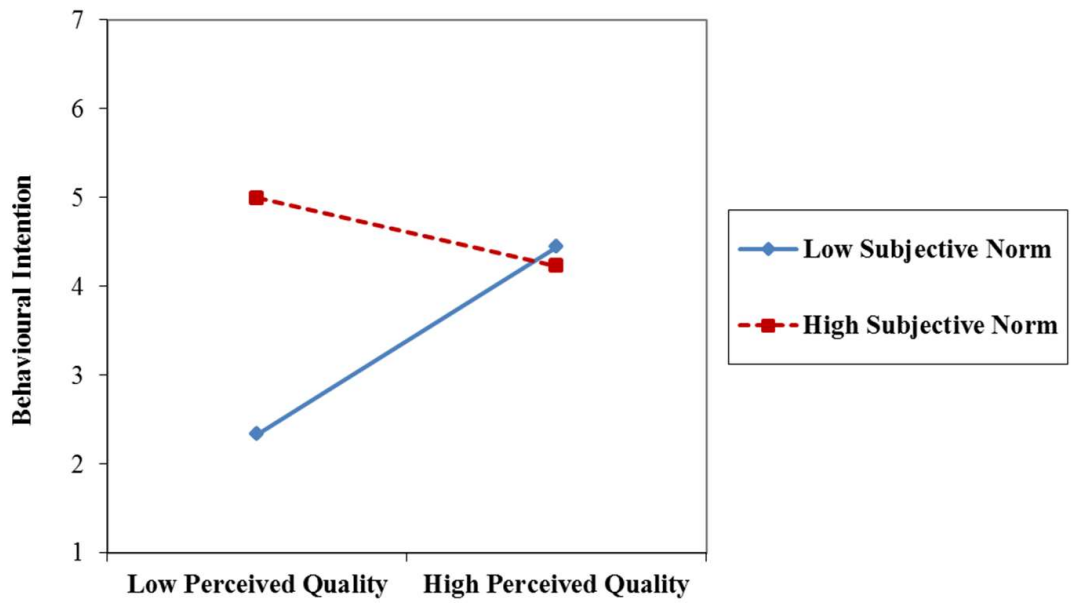

Figure 3 The interaction of perceived quality and subjective norm on behavioural intention

Previous studies on UGS showed that demographic variable could be a dominated factor influencing the use of UGS (e.g. Jim \& Shan, 2013; Lo \& Jim, 2012; Payne, Mowen, \& Orsega-Smith, 2002; Shan, 2014; Wang \& Zhao, 2017). Generally, significant different were found among different socio-demographic groups. To account for the impact of the respondents' demographic background in this study, gender, age education level, and monthly income were included as independent variables in Model 4. The significant relationships found in Model 3 (i.e. without controlling the demographic variables) remained unchanged in Model 4, and inclusion of the control variables did not greatly increase the variance explained $\left(R^{2}\right)$. The demographic variables did not cause significant impact on the explanatory power of proposed predictors in the current study. Besides, only gender and age were significantly correlated with behavioural intention. Since demographic variables were not the focal variables in this study and their impacts on UGS preferences and usage have been excessively studied in existing literature (Grove et al., 2006), their effects on the dependent variable would not be further investigated and discussed in this study.

Regarding the goodness of fit of the model, in contrast with covariance-based structural equation modeling (e.g. analysis computed by LISREL or AMOS), PLS provides only a single goodness of fit (GoF) measure (Henseler \& Sarstedt, 2013). GoF in PLS can be computed as geometric mean of the average communality and the average $R^{2}$ (Tenenhaus et al., 2005). GoF values of $0.35,0.50$ and 0.61 can be interpreted as small, medium and large, respectively (Latan \& Ghozali, 2012). The GoF value of the model proposed in this study (i.e. Model 3) was 0.626 , implying that the model is statistically fit. 


\section{Discussion}

The TPB laid a useful foundation in explaining usage of UGS. The three variables, attitude, subjective norm, and perceived behaviour control were significantly correlated with behavioural intention (Model 1 in Table 4). This finding is consistent with those empirical studies in various fields as discussed above (Ajzen, 1991; Rhodes et al., 2006; Wang et al., 2015). The additional variable, usefulness, was found to be a power predictor, contributing around $30 \%$ of the variance in behavioural intention of using UGS (Table 5). The results indicated that considerable proportion of residual variance in intention of using urban green areas is captured by constructs other than those proposed in the original TPB. The parsimonious nature, a wide range of applicability, and flexibility of predictor inclusion make the TPB as a starting point for identifying key variables of UGS utilization behaviour and understanding the direction and strength of relationships between variables.

The current study presents the multidimensional nature of attitude towards UGS and their role in shaping man-nature interaction processes. The significant relationship between usefulness and behavioural intention is consistent with the findings by Balram and Dragićević (2005). It is worth noting that the contribution to variance explained by usefulness $(30.85 \%)$ is higher than those by attitude towards urban green spaces (13.58\%), implying that usefulness (i.e. specific attitude) is superior predictor of intention to use UGS compared with attitude towards UGS (i.e. general attitude). The finding corroborates the argument by Stern, Dietz, and Guagnano (1995) that the impact of general attitude on behaviour is not conclusive. Compared with general attitude towards urban green spaces, specific attitude towards UGS visiting behaviour is more accurate in predicting behavioural intention (see also Do Valle et al., 2005). Moreover, statistical findings of this study stressed the predictive importance of instrumental attitude (i.e. usefulness) over experiential attitude (i.e. perceived quality) (Model 2 ). The insignificant relationship between perceived quality and behavioural intention suggests that experiential attitude is not necessary a predictor of UGS visiting behaviour. The absence of significant relationship between experiential attitude and behavioural intention has been documented by some studies, for instance, Rhodes and Courneya (2005) found that a positive linear relationship between instrumental attitude and behaviour, but experiential attitude is only correlated with high level of intention to exercise. Affective feelings in study by Catellier and Yang (2013) did not show great influence on people's intention to exercise. The greater potential of specific and instrumental attitude in shaping UGS utilization behaviour advances our conceptual understanding of attitude in relation to people-environment interaction processes. 
The moderating effects of subjective norm found in the current research give insight into the mechanisms of social processes in influencing predictors of behavioural intention. Two of the four moderating effects (i.e. H8, usefulness and subjective norm; H9, perceived quality and subjective norm) were negatively significant. The powerful social pressure experienced by individuals override the effect of usefulness and perceived quality on behavioural intention. According to the simple slope analysis (Figure 2 and 3), even if individuals possess low level of usefulness or perceived quality of UGS, they would still have a strong intention to visit UGS under the influence of high level of perceived subjective norm. Another point worth noting is that perceived quality acting separately does not yield a significant prediction (Model 2); however, when coupled with subjective norm the interaction term (i.e. $\mathrm{PQ} \times \mathrm{SN}$ ) becomes reliable capacity for prediction (Model 3). In sum, two interaction terms vary as a function of subjective norm. The findings unveil the underlying mechanisms of social influence that may affect UGS utilization behaviour, and give empirical evidence to Raymore's (2002) argument that interpersonal facilitators such as peers and family promote leisure participation and shape our leisure preferences (see also Crawford, Jackson, \& Godbey, 1991).

These results suggested important implications to public authorities for encouraging the use of UGS and, in turn, improve physical / psychological health and social cohesiveness (Coley et al., 1997; Kaplan, 1995; Maas et al., 2009; Ulrich, 1981). The major considerations for public promotion can be inferred from these results including:

- Positioning the visit to urban green spaces as a social trend in order to sharpen the subjective norm among individuals. For example, the promotional message may highlight the popularity of using UGS in the city. In addition, as subjective norm relates to the expectation and behaviour of significant others, promotional campaigns may be presented by a celebrity who can serve as a role model. Interestingly however, the negative moderating effect of subjective norm on relationship between usefulness and perceived quality implies that unified intervention strategies would not reach maximized efficiency. For people who are subject to high level of social influence, messages stressing the usefulness and quality of UGS are not effective to boost behavioural intention. By contrast, interventions which enhance the usefulness and perceived quality of UGS are convincing for individuals with less perceived subjective norm. Therefore, intervention strategies should be separately designed that target on people with high or low level of social influence.

- Usefulness was found to be a powerful predictor of UGS usage in the present study. Enhancing the understanding of benefits of using urban green spaces among individuals 
would heighten their perceived usefulness of UGS. Since activity is the result of interaction between the presence of environmental resources and individuals' pursuit of goals (Curl, Thompson, Alves, \& Aspinall, 2016), spreading messages that UGS provides supports for goal realization would be critical to enhancing frequency of use among people. According to Lo and Jim (2012), Hong Kong citizens generally put a heavier emphasis on recreational functions of UGS, but not environmental and social functions. In this regard, public authorities may highlight the enjoyments of visiting UGS and illustrate the potential psychological and physical benefits associated with contacting green environment for individuals.

- Accessibility and convenience of UGS improve individuals' PBC of visiting urban green environment. Activities and events require the use of space and material resources to complete (Little, 1983) and in this case UGS is an open space which enables people to carry out a variety of acts for maintaining a state of affairs. Though small UGS at neighbourhood levels are easily accessible in Hong Kong, Lo and Jim (2012) revealed that Hong Kong residents prefer large scale of UGS. Large size of open green spaces provide a sense of spaciousness which allows users to move freely and participate in different kinds of activities without being disturbed or disturbing other users (Björk et al., 2008; Neuvonen, Sievänen, Tönnes, \& Koskela, 2007). There is an ongoing quest for conveniently located and large scale parks among Hong Kong citizens. Besides, given that $\mathrm{PBC}$ is related to individuals' knowledge that determine behaviour engagement, directional signage of UGS and instructions of facilities usage may help to enhance PBC of individuals (Wan \& Shen, 2015a). Similarly, Wang et al. (2015) suggested that users' perception of UGS accessibility are multidimensional, physical UGS characteristics together with non-physical factors such as safety and users' preference should be carefully considered by planning authorities.

There were several limitations in this study that should be addressed in future research. The study was conducted in Hong Kong with a relatively small sample size and the findings may not be generalised to other cities. The lower education group was under-represented in the sample. Therefore, further research may attempt to test the model in other contexts with a larger and more representative sample. Self-reported measures were used in this study that may cause reporting bias. In the study of recycling behaviour by Huffman, Van Der Werff, Henning, and Watrous-Rodriguez (2014), self-reported and observed behaviour are correlated but the correlation is not strong. Future study may consider investigating both self-reported and observed behaviour and the association / differences between the two. Lastly, the growing use of mobile phone implies that specific population group such as young people may be excluded from landline telephone survey. To avoid under-representation of this 
population group, future study may need to combine samples from both landline telephone and mobile phone users.

\section{Conclusions}

This study extended the theory of planned behaviour to explain behaviour of using urban green spaces and the moderating effect of subjective norm on behavioural intention. The results showed that subjective norm, perceived behavioural control, and usefulness are important predictors in predicting behavioural intention of using UGS. In addition, subjective norm negatively moderated the relationship between usefulness and behavioural intention. The interaction of perceived quality and subjective norm significantly influenced behavioural intention. This study based on TPB, a robust model in attitude-behaviour study, filled the gap of the literature by investigating the moderating role of subjective norm. The extended model helps policy makers better understand the factors influencing intention to use UGS. It facilitates the promotion of using UGS. Specifically, promotional campaigns may focus on positioning the use of UGS as a social trend. In addition, highlighting the benefits of UGS use and its accessibility would also increase the users' intention to use. Users would benefit with respect to initiating restorative processes, improved quality of life and sense of social cohesiveness. 


\section{References}

Ajzen, I. (1988). Attitudes, Personality and Behavior. Milton Keynes: Open University Press.

Ajzen, I. (1991). The theory of planned behavior. Organizational Behavior and Human Decision Processes, 50(2), 179-211.

Ajzen, I., \& Driver, B. (1992). Application of the theory of planned behavior to leisure choice. Journal of Leisure Research, 24(3), 207-24.

Ajzen, I., \& Madden, T.J. (1986). Prediction of goal directed behavior: Attitudes, intentions, and perceived behavioral control. Journal of Experimental Social Psychology, 22, 453-74.

Akter, S., D'Ambra, J., \& Ray, P. (2011). An evaluation of PLS based complex models: the roles of power analysis, predictive relevance and GoF index. AMCIS 2011 Proceedings-All Submissions.

Armitage, C.J., \& Conner, M. (2001). Efficacy of the theory of planned behaviour: A metaanalytic review. British Journal of Social Psychology, 40(4), 471-99.

Balram, S., \& Dragićević, S. (2005). Attitudes toward urban green spaces: integrating questionnaire survey and collaborative GIS techniques to improve attitude measurements. Landscape and Urban Planning, 71(2), 147-62.

Bamberg, S., Ajzen, I., \& Schmidt, P. (2003). Choice of travel mode in the theory of planned behavior: The roles of past behavior, habit, and reasoned action. Basic and Applied Social Psychology, 25(3), 175-87.

Bamberg, S., \& Schmidt, P. (2003). Incentives, morality, or habit? Predicting students' car use for university routes with the models of Ajzen, Schwartz, and Triandis. Environment and Behavior, 35(2), 264-85.

Bandura, A. (1989). Human agency in social cognitive theory. American Psychologist, 44(9), 1175-84.

Berg, C., Jonsson, I., \& Conner, M. (2000). Understanding choice of milk and bread for breakfast among Swedish children aged 11-15 years: an application of the theory of planned behaviour. Appetite, 34(1), 5-19.

Björk, J., Albin, M., Grahn, P., Jacobsson, H., Ardö, J., Wadbro, J., Östergren, P.-O., \& Skärbäck, E. (2008). Recreational values of the natural environment in relation to neighbourhood satisfaction, physical activity, obesity and wellbeing. Journal of Epidemiology and Community Health, 62, e2.

Bonnes, M., Passafaro, P., \& Carrus, G. (2011). The ambivalence of attitudes toward urban green areas: Between proenvironmental worldviews and daily residential experience. Environment and Behavior, 43(2), 207-32.

Caldwell, L.L., \& Darling, N. (1999). Leisure context, parental control, and resistance to peer pressure as predictors of adolescent partying and substance use: An ecological 
perspective. Journal of Leisure Research, 31(1), 57-77.

Carrus, G., Passafaro, P., \& Bonnes, M. (2004). Environmentalism, ethnocentrism and authoritarianism: an attitude toward urban green scale. Bollettino di Psicologia Applicata, 242, 3-12.

Catellier, J.R.A., \& Yang, Z.J. (2013). The role of affect in the decision to exercise: Does being happy lead to a more active lifestyle? Psychology of Sport and Exercise, 14(2), 275-82.

Census and Statistics Department. (2011). 2011 Population Census. Hong Kong: The Government of Hong Kong Special Adminstrative Region Retrieved from http://www.census2011.gov.hk/en/index.html.

Chan, K. (1998). Mass communication and pro-environmental behaviour: waste recycling in Hong Kong. Journal of Environmental Management, 52(4), 317-25.

Chen, M.-F., \& Tung, P.-J. (2010). The Moderating Effect of Perceived Lack of Facilities on Consumers' Recycling Intentions. Environment and Behavior, 42(6), 824-44.

Cheung, R., \& Vogel, D. (2013). Predicting user acceptance of collaborative technologies: An extension of the technology acceptance model for e-learning. Computers \& Education, 63, 160-75.

Chi, H., Yeh, H., \& Hung, W.-c. (2012). The moderating effect of subjective norm on cloud computing users' perceived risk and usage intention. International Journal of Marketing Studies, 4(6), 95-102.

Chin, W.W. (1998). Commentary: Issues and opinion on structural equation modeling. MIS Quarterly, 22(1), vii-xvi.

Cialdini, R.B., Kallgren, C.A., \& Reno, R.R. (1991). A focus theory of normative conduct: A theoretical refinement and reevaluation of the role of norms in human behavior. Advances in Experimental Social Psychology, 24, 201-34.

Cialdini, R.B., Reno, R.R., \& Kallgren, C.A. (1990). A focus theory of normative conduct: recycling the concept of norms to reduce littering in public places. Journal of Personality and Social Psychology, 58(6), 1015-26.

Coen, S.E., \& Ross, N.A. (2006). Exploring the material basis for health: Characteristics of parks in Montreal neighborhoods with contrasting health outcomes. Health \& Place, 12(4), 361-71.

Cohen, J. (1988). Statistical Power Analysis for the Behavioral Sciences. Hillsdale, N.J.: L. Erlbaum Associates.

Coley, R.L., Sullivan, W.C., \& Kuo, F.E. (1997). Where does community grow? The social context created by nature in urban public housing. Environment and Behavior, 29(4), 468-94.

Crawford, D.W., Jackson, E.L., \& Godbey, G. (1991). A hierarchical model of leisure constraints. Leisure Sciences, 13(4), 309-20. 
Curl, A., Thompson, C.W., Alves, S., \& Aspinall, P. (2016). Outdoor Environmental Supportiveness and Older People's Quality of Life: A Personal Projects Approach. Journal of Housing for the Elderly, 30(1), 1-16.

Davies, J., Foxall, G., \& Pallister, J. (2002). Beyond the intention-behaviour mythology an integrated model of recycling. Marketing Theory, 2(1), 29-113.

De Vries, S., Van Dillen, S.M.E., Groenewegen, P.P., \& Spreeuwenberg, P. (2013). Streetscape greenery and health: Stress, social cohesion and physical activity as mediators. Social Science \& Medicine, 94, 26-33.

De Vries, S., Verheij, R.A., Groenewegen, P.P., \& Spreeuwenberg, P. (2003). Natural environments-healthy environments? An exploratory analysis of the relationship between greenspace and health. Environment and Planning A, 35(10), 1717-32.

Do Valle, P.O., Rebelo, E., Reis, E., \& Menezes, J. (2005). Combining behavioral theories to predict recycling involvement. Environment and Behavior, 37(3), 364-96.

Faul, F., Erdfelder, E., Lang, A.-G., \& Buchner, A. (2007). G* Power 3: A flexible statistical power analysis program for the social, behavioral, and biomedical sciences. Behavior Research Methods, 39(2), 175-91.

Fishbein, M., \& Ajzen, I. (1975). Belief, Attitude, Intention, and Behavior: An Introduction to Theory and Research. Reading, Mass.: Addison-Wesley Pub. Co.

Fornell, C., \& Larcker, D.F. (1981). Evaluating structural equation models with unobservable variables and measurement error. Journal of Marketing Research, 39-50.

Francis, J., Giles-Corti, B., Wood, L., \& Knuiman, M. (2012). Creating sense of community: The role of public space. Journal of Environmental Psychology, 32(4), 401-09.

Glanz, K., Rimer, B.K., \& Viswanath, K. (Eds.). (2008). Health Behavior and Health Education: Theory, Research, and Practice. San Francisco, CA: JOssey-Bass.

Grahn, P., \& Stigsdotter, U.K. (2010). The relation between perceived sensory dimensions of urban green space and stress restoration. Landscape and Urban Planning, 94(3), 264-75.

Grove, J., Troy, A., O’Neil-Dunne, J., Burch Jr, W., Cadenasso, M., \& Pickett, S. (2006). Characterization of households and its implications for the vegetation of urban ecosystems. Ecosystems, 9(4), 578-97.

Hair, J.F., Black, W.C., Babin, B.J., \& Anderson, R.E. (Eds.). (2013). Multivariate Data Analysis. Harlow, United Kingdom: Pearson Education, Limited.

Hair, J.F., Ringle, C.M., \& Sarstedt, M. (2011). PLS-SEM: Indeed a silver bullet. The Journal of Marketing Theory and Practice, 19(2), 139-52.

Hamilton, K., \& White, K., M. (2008). Extending the Theory of Planned Behavior: The Role of Self and Social Influences in Predicting Adolescent Regular Moderate-to-Vigorous Physical Activity. Journal of Sport \& Exercise Psychology, 30(1), 56-74.

Hartig, T., Mang, M., \& Evans, G.W. (1991). Restorative effects of natural environment experiences. Environment and Behavior, 23(1), 3-26. 
Hartig, T., Mitchell, R., de Vries, S., \& Frumkin, H. (2014). Nature and Health. Annual Review of Public Health, 35, 207-28.

Heath, Y., \& Gifford, R. (2002). Extending the theory of planned behavior: predicting the use of public transportation. Journal of Applied Social Psychology, 32(10), 2154-89.

Henseler, J., \& Sarstedt, M. (2013). Goodness-of-fit indices for partial least squares path modeling. Computational Statistics, 28(2), 565-80.

Huffman, A.H., Van Der Werff, B.R., Henning, J.B., \& Watrous-Rodriguez, K. (2014). When do recycling attitudes predict recycling? An investigation of self-reported versus observed behavior. Journal of Environmental Psychology, 38, 262-70.

Jim, C., \& Shan, X. (2013). Socioeconomic effect on perception of urban green spaces in Guangzhou, China. Cities, 31, 123-31.

Jöreskog, K.G., \& Sörbom, D. (1989). LISREL 7: A guide to the program and applications. Chicago, Ill.: SPSS.

Kaczynski, A.T., Potwarka, L.R., Smale, B.J., \& Havitz, M.E. (2009). Association of Parkland Proximity with Neighborhood and Park-based Physical Activity: Variations by Gender and Age. Leisure Sciences, 31(2), 174-91.

Kaplan, S. (1995). The restorative benefits of nature: Toward an integrative framework. Journal of Environmental Psychology, 15(3), 169-82.

Keizer, K., Lindenberg, S., \& Steg, L. (2011). The reversal effect of prohibition signs. Group Processes \& Intergroup Relations, 14(5), 681-88.

Koohsari, M.J., Mavoa, S., Villanueva, K., Sugiyama, T., Badland, H., Kaczynski, A.T., Owen, N., \& Giles-Corti, B. (2015). Public open space, physical activity, urban design and public health: Concepts, methods and research agenda. Health \& Place, 33, 75-82.

Lachowycz, K., \& Jones, A.P. (2011). Greenspace and obesity: a systematic review of the evidence. Obesity Reviews, 12(5), e183-e89.

Lam, T., Baum, T., \& Pine, R. (2003). Subjective norms: effects on job satisfaction. Annals of Tourism Research, 30(1), 160-77.

Latan, H., \& Ghozali, I. (2012). Partial least Squares: Concept and application path modeling using program XLSTAT-PLS for empirical research, BP UNDIP.

Lau, S. (2015, 16 June). Hong Kong pollsters prefer to stick with landline phones for surveys, instead of mobile devices. South China Morning Post. Retrieved from http://www.scmp.com/news/hong-kong/politics/article/1822633/hong-kong-pollsters-pref er-stick-landline-phones-surveys

Limayem, M., \& Cheung, C.M. (2011). Predicting the continued use of Internet-based learning technologies: the role of habit. Behaviour \& Information Technology, 30(1), 91-99.

Little, B.R. (1983). Personal Projects A Rationale and Method for Investigation. Environment and Behavior, 15(3), 273-309. 
Lo, A.Y., \& Jim, C. (2010). Differential community effects on perception and use of urban greenspaces. Cities, 27(6), 430-42.

Lo, A.Y., \& Jim, C. (2012). Citizen attitude and expectation towards greenspace provision in compact urban milieu. Land Use Policy, 29(3), 577-86.

Lu, I.R., Kwan, E., Thomas, D.R., \& Cedzynski, M. (2011). Two new methods for estimating structural equation models: An illustration and a comparison with two established methods. International Journal of Research in Marketing, 28(3), 258-68.

Maas, J., Van Dillen, S.M., Verheij, R.A., \& Groenewegen, P.P. (2009). Social contacts as a possible mechanism behind the relation between green space and health. Health \& Place, 15(2), 586-95.

Malhotra, N.K. (2012). Basic Marketing Research: Integration of Social Media. Upper Saddle River, N.J.; Harlow: Pearson.

Manning, M. (2009). The effects of subjective norms on behaviour in the theory of planned behaviour: A meta-analysis. British Journal of Social Psychology, 48, 649-705.

Massey, J.T., O’Connor, D., \& Krotki, K. (1997). Response rates in random digit dialing (RDD) telephone surveys. Paper presented at the Proceedings of the American Statistical Association, Section on Survey Research Methods.

Neuman, W.L. (2013). Social Research Methods: Qualitative and Quantitative Approaches. Harlow, England: Pearson Education Ltd.

Neuvonen, M., Sievänen, T., Tönnes, S., \& Koskela, T. (2007). Access to green areas and the frequency of visits-A case study in Helsinki. Urban Forestry \& Urban Greening, 6(4), 235-47.

Nielsen, T.S., \& Hansen, K.B. (2007). Do green areas affect health? Results from a Danish survey on the use of green areas and health indicators. Health \& Place, 13(4), 839-50.

Nordh, H., Hartig, T., Hagerhall, C.M., \& Fry, G. (2009). Components of small urban parks that predict the possibility for restoration. Urban Forestry \& Urban Greening, 8(4), 225-35.

Payne, L.L., Mowen, A.J., \& Orsega-Smith, E. (2002). An examination of park preferences and behaviors among urban residents: the role of residential location, race, and age. Leisure Sciences, 24(2), 181-98.

Povey, R., Conner, M., Sparks, P., James, R., \& Shepherd, R. (2000). Application of the Theory of Planned Behaviour to two dietary behaviours: Roles of perceived control and self-efficacy. British Journal of Health Psychology, 5(2), 121-39.

Raymore, L.A. (2002). Facilitators to leisure. Journal of Leisure Research, 34(1), 37.

Reinartz, W., Haenlein, M., \& Henseler, J. (2009). An empirical comparison of the efficacy of covariance-based and variance-based SEM. International Journal of Research in Marketing, 26(4), 332-44.

Rhodes, R.E., Brown, S.G., \& McIntyre, C.A. (2006). Integrating the perceived 
neighborhood environment and the theory of planned behavior when predicting walking in a Canadian adult sample. American Journal of Health Promotion, 21(2), 110-18.

Rhodes, R.E., \& Courneya, K.S. (2005). Threshold assessment of attitude, subjective norm, and perceived behavioral control for predicting exercise intention and behavior. Psychology of Sport and Exercise, 6(3), 349-61.

Ringle, C.M., Wende, S., \& Will, S. (2005). SmartPLS 2.0 (M3) Beta, Hamburg.

Schipperijn, J., Bentsen, P., Troelsen, J., Toftager, M., \& Stigsdotter, U.K. (2013). Associations between physical activity and characteristics of urban green space. Urban Forestry \& Urban Greening, 12(1), 109-16.

Schipperijn, J., Ekholm, O., Stigsdotter, U.K., Toftager, M., Bentsen, P., Kamper-Jørgensen, F., \& Randrup, T.B. (2010). Factors influencing the use of green space: Results from a Danish national representative survey. Landscape and Urban Planning, 95(3), 130-37.

Schipperijn, J., Stigsdotter, U.K., Randrup, T.B., \& Troelsen, J. (2010). Influences on the use of urban green space-A case study in Odense, Denmark. Urban Forestry \& Urban Greening, 9(1), 25-32.

Schultz, P.W., Nolan, J.M., Cialdini, R.B., Goldstein, N.J., \& Griskevicius, V. (2007). The constructive, destructive, and reconstructive power of social norms. Psychological Science, 18(5), 429-34.

Shan, X.-Z. (2014). Socio-demographic variation in motives for visiting urban green spaces in a large Chinese city. Habitat International, 41, 114-20.

Shih, Y.-Y., \& Fang, K. (2004). The use of a decomposed theory of planned behavior to study Internet banking in Taiwan. Internet Research, 14(3), 213-23.

Smith, J., R., Louis, W.R., Terry, D.J., Greenaway, K.H., Clarke, M.R., \& Cheng, X. (2012). Congruent or conflicted? The impact of injunctive and descriptive norms on environmental intentions. Journal of Environmental Psychology, 32(4), 353-61.

Stern, P.C. (1992). Psychological dimensions of global environmental change. Annual Review of Psychology, 43(1), 269-302.

Stern, P.C., Dietz, T., \& Guagnano, G.A. (1995). The new ecological paradigm in social-psychological context. Environment and Behavior, 27(6), 723-43.

Sugiyama, T., Leslie, E., Giles-Corti, B., \& Owen, N. (2008). Associations of neighbourhood greenness with physical and mental health: do walking, social coherence and local social interaction explain the relationships? Journal of Epidemiology and Community Health, 62, e9.

Sugiyama, T., \& Thompson, C.W. (2007). Older people's health, outdoor activity and supportiveness of neighbourhood environments. Landscape and Urban Planning, 83(2), 168-75.

Tenenhaus, M., Vinzi, V.E., Chatelin, Y.-M., \& Lauro, C. (2005). PLS path modeling. Computational Statistics \& Data Analysis, 48(1), 159-205. 
Thompson, C.W. (2013). Activity, exercise and the planning and design of outdoor spaces. Journal of Environmental Psychology, 34, 79-96.

Ulrich, R.S. (1981). Natural versus urban scenes some psychophysiological effects. Environment and Behavior, 13(5), 523-56.

Ulrich, R.S., Simons, R.F., Losito, B.D., Fiorito, E., Miles, M.A., \& Zelson, M. (1991). Stress recovery during exposure to natural and urban environments. Journal of Environmental Psychology, 11(3), 201-30.

Van den Berg, A.E., Joyce, Y., \& De Vries, S. (2012). Health benefits of nature. In L. Steg, et al. (Eds.), Environmental Psychology: An Introduction. Chichester, West Sussex; Malden, MA: BPS Blackwell.

Van den Berg, A.E., Maas, J., Verheij, R.A., \& Groenewegen, P.P. (2010). Green space as a buffer between stressful life events and health. Social Science \& Medicine, 70(8), 1203-10.

Wan, C., Cheung, R., \& Shen, G.Q. (2012). Recycling attitude and behaviour in university campus: a case study in Hong Kong. Facilities, 30(13/14), 630-46.

Wan, C., \& Shen, G.Q. (2015a). Encouraging the use of urban green space: The mediating role of attitude, perceived usefulness and perceived behavioural control. Habitat International, 50, 130-39.

Wan, C., \& Shen, G.Q. (2015b). Salient attributes of urban green spaces in high density cities: The case of Hong Kong. Habitat International, 49, 92-99.

Wan, C., Shen, G.Q., \& Choi, S. (2017). Experiential and instrumental attitudes: Interaction effect of attitude and subjective norm on recycling intention. Journal of Environmental Psychology, 50, 69-79.

Wan, C., Shen, G.Q., \& Yu, A. (2014). The role of perceived effectiveness of policy measures in predicting recycling behaviour in Hong Kong. Resour. Conserv. Recycl., 83, 141-51.

Wang, D., Brown, G., Liu, Y., \& Mateo-Babiano, I. (2015). A comparison of perceived and geographic access to predict urban park use. Cities, 42, 85-96.

Wang, R., \& Zhao, J. (2017). Demographic groups' differences in visual preference for vegetated landscapes in urban green space. Sustainable Cities and Society, 28, 350-57.

WHO. (2016). Urban green spaces and health. Copenhagen: WHO Regional Office for Europe.

Wong, K.K. (2009). Urban park visiting habits and leisure activities of residents in Hong Kong, China. Managing Leisure, 14(2), 125-40.

Yung, E.H., Conejos, S., \& Chan, E.H. (2016). Social needs of the elderly and active aging in public open spaces in urban renewal. Cities, 52, 114-22. 


\section{Appendix A}

\begin{tabular}{|c|c|c|}
\hline \multirow{2}{*}{$\begin{array}{l}\text { Constructs } \\
\text { Attitude (ATT) }\end{array}$} & \multicolumn{2}{|r|}{ Indicators } \\
\hline & ATT1 & If one had more contact with nature in the city, he/she would feel less stress. \\
\hline & ATT2 & The presence of green in the city makes us feel more alive. \\
\hline & ATT3 & In the city people need nature for psychological restoration. \\
\hline & ATT4 & In the city one can ease tensions just by watching a green area. \\
\hline & ATT5 & $\begin{array}{l}\text { Being in a city green area can also help to improve the relationships with } \\
\text { others. }\end{array}$ \\
\hline \multirow{4}{*}{$\begin{array}{l}\text { Subjective Norm } \\
\text { (SN) }\end{array}$} & SN1 & Most people would think that using urban green spaces is a good idea. \\
\hline & SN2 & My friends would think I should use urban green spaces. \\
\hline & $\mathrm{SN} 3$ & My family would think I should use urban green spaces. \\
\hline & SN4 & My co-workers or schoolmates would think I should use urban green spaces. \\
\hline Perceived & PBC1 & I have plenty of opportunities to use urban green spaces. \\
\hline Behavioural & $\mathrm{PBC} 2$ & I have enough time to use urban green spaces. \\
\hline \multirow[t]{4}{*}{ Control (PBC) } & $\mathrm{PBC} 3$ & Using urban green spaces is convenient and easy. \\
\hline & $\mathrm{PBC} 4$ & I know where urban green spaces are. \\
\hline & PBC5 & I know how to go to urban green spaces. \\
\hline & PBC6 & I know how to use the facilities at urban green spaces. \\
\hline \multirow[t]{4}{*}{ Usefulness (USE) } & USE1 & I use urban green spaces to relax. \\
\hline & USE2 & I use urban green spaces for recreation. \\
\hline & USE3 & Urban green spaces contribute to my quality of life. \\
\hline & USE4 & Urban green spaces would increase my property value. \\
\hline \multirow{4}{*}{$\begin{array}{l}\text { Perceived Quality } \\
\text { (PQ) }\end{array}$} & PQ1 & There are enough urban green spaces. \\
\hline & PQ2 & Urban green spaces are in good condition. \\
\hline & PQ3 & The urban green spaces are well-equipped \\
\hline & PQ4 & Most urban green spaces are closed to the public. \\
\hline \multirow{3}{*}{$\begin{array}{l}\text { Behavioural } \\
\text { Intention (BI) }\end{array}$} & BI1 & I plan to visit / use urban green spaces. \\
\hline & BI2 & I intend to visit / use urban green spaces in the next 4 weeks. \\
\hline & BI3 & I will visit / use urban green spaces every time I have an opportunity. \\
\hline
\end{tabular}

